\title{
Relationship between Body Mass Index, Preoccupation towards Food and Subjective Well-being among young adults
}

\author{
Ms. Priya Magesh ${ }^{1 *}$, Ms. Madhumita Shankar ${ }^{2}$
}

${ }^{1}$ Assistant Professor and Head Department of Psychology, Madras School of Social work, Egmore, Chennai-08, India

${ }^{2}$ UG Student, Department of Psychology, Madras School of Social work, Egmore, Chennai-08, India

DOI: $10.36347 /$ sjahss.2020.v08i03.005

| Received: 06.03.2020 | Accepted: 13.03.2020 | Published: 27.03.2020

*Corresponding author: Priya Magesh

Abstract

A young adult is generally a person in the age range of 20 to 39 (or 40), whereas an adolescent is a person aging from 13 to 19, although definitions and opinions, such as Erik Erikson's stages of human development, vary. The young adult stage in human development precedes middle adulthood. The body mass index (BMI) or Quetelet index is a value derived from the mass (weight) and height of an individual. The Body Mass Index is defined as the body mass divided by the square of the body height, and is universally expressed in units of $\mathrm{kg} / \mathrm{m} 2$, resulting from mass in kilograms and height in metres. Thoughts, feelings and behaviours related to managing food and weight can begin to interfere with our everyday activities. When focus is too much on our bodies and our eating, these preoccupations can quickly lead to missed opportunities in other parts of our lives. Our personal, school or professional lives, not to mention our overall well-being, can be drastically affected. Food and weight preoccupation can also lead to severe physical and emotional problems. Affect balance refers to the emotions, moods and feelings a person has. This can be all positive, all negative or a combination of both positive and negative. Some research shows also that feelings of reward are separate from positive and negative affect. There is evidence that health and Subjective Wellbeing may mutually influence each other, as good health tends to be associated with greater happiness and a number of studies have found that positive emotions and optimism can have a beneficial influence on health.

Keywords: Body mass Index, Preoccupation towards food, Subjective wellbeing, Young adults.

Copyright @ 2020: This is an open-access article distributed under the terms of the Creative Commons Attribution license which permits unrestricted use, distribution, and reproduction in any medium for non-commercial use (NonCommercial, or CC-BY-NC) provided the original author and source are credited.

\section{INTRODUCTION}

Young/prime adulthood can be considered the healthiest time of life and young adults are generally in good health, subject neither to disease nor the problems of senescence. Biological function and physical performance reach their peak from 20-35 years of age, waning after 35 . Strength peaks around 25 years of age, plateaus through 35-40 years of age, and then declines. Flexibility also decreases with age throughout adulthood. However, there are large individual differences and a fit 40-year-old may out-compete a sedentary 20-year-old. In developed countries, mortality rates for the 18-40 age group are typically very low. Men are more likely to die at this age than women, particularly in the 18-25 group: reasons include car accidents and suicide. Mortality statistics among men and women level off during the late twenties and thirties, due in part to good health and less risk-taking behaviour. According to Erikson, in the wake of the adolescent emphasis upon identity formation, 'the young adult, emerging from the search for and insistence on identity, is eager and willing to fuse his identity with that of others. He [or she] is ready for intimacy, that is, the capacity to commit...to concrete affiliations and partnerships. To do so means the ability 'to face the fear of ego loss in situations which call for self-abandon. Avoidance of such experiences 'because of a fear of ego-loss may lead to a deep sense of isolation and consequent self-absorption'.

The Body Mass Index may also be determined using a table or chart which displays Body Mass Index as a function of mass and height using contour lines or colours for different Body Mass Index categories, and may use two different units of measurement. The Body Mass Index is an attempt to quantify the amount of tissue mass (muscle, fat, and bone) in an individual, and then categorize that person as underweight, normal weight, overweight, or obese based on that value. However, there is some debate about where on the Body Mass Index scale the dividing lines between categories should be placed. Commonly accepted Body Mass Index ranges are underweight: underweight: 18.5, 
normal weight: 18.5 to 25 , overweight: 25 to 30 , obese: over 30 .

Food addiction is a disorder characterized by preoccupation with food, the availability of food and the anticipation of pleasure from the ingestion of food. Food addiction involves the repetitive consumption of food against the individual's better judgment resulting in loss of control and preoccupation or the restriction of food and preoccupation with body weight and image. There are many societal, familial and individual factors that can influence the development of an eating disorder. Individuals who are struggling with their identity and self-image can be at risk, as well as those who have experienced a traumatic event. Eating disorders can also be a product of how one has been raised and taught to behave. Usually, an eating disorder signals that the person has deep emotional difficulties that they are unable to face or resolve. People with eating disorders often describe a feeling of powerlessness. By manipulating their eating, they then blunt their emotions or get a false sense of control in their lives. In this way, an eating disorder develops out of a method of coping with the world. This coping, however, is merely a mask, as it does not solve the life problems that the person is experiencing.

There is abundant literature on the control of eating which emphasizes physiological mechanisms [1, 2]. In particular, humans are endowed with a biological weight regulation system that favours weight gain over weight loss in order to reduce any future risk of starvation. While this regulation mechanism was advantageous to human evolutionary development, today it may challenge the individual's conscious control of food intake. As a result, people might consume more food and calories and eat more frequently than they consider good for themselves or than their planned diet prescribes.

Food oftentimes becomes the main topic of conversation, reading, dreams, papers, etc. Individuals frequently will seek employment that puts them in contact with food i.e. chef, waitress, server, food preparation. A common symptom of starvation is hoarding of food and non-food related items, saving or collecting but not with the intention of consuming. These are all ways of being surrounded by food however not ingesting it. In the Minnesota starvation study, it was observed that subjects continued to be plagued by incessant thoughts of food and eating. Food became a principal topic of conversation, reading, and daydreams. Preoccupation with food or reliance on food is simply just a symptom of something else going on of a need that isn't being met. Human beings have real needs, and on a deep level, when those needs aren't met, they try to meet them. For many women, that shows up in their relationship with food. People turn to food to feel the way they want to feel - comforted, loved, excited, and happy. They turn to food to distract themselves from something that they can't bear to think about or to feel. They obsess over food as a way to control their environment and their weight and to guarantee that they'll feel happy and safe. They start a new diet for a sense of belonging in the community.

Subjective wellbeing may be considered "a general area of scientific interest rather than a single specific construct." Components of SWB relating to the affect include positive affect (experiencing pleasant emotions) and low negative affect (experiencing unpleasant, distressing moods), as well as "overall affect" or "hedonic balance", defined as the overall equilibrium between positive and negative affect and usually measured as the difference between the two. There are two components of Subjective wellbeing: one is Affect Balance and the other is Life Satisfaction. Another important factor of well-being is that it only focuses on an individual's internal state rather than examining their external experiences. Although much emphasis is given to the respondent's long-term mood rather than a momentary mood, a concrete evaluation of an individual's mental health cannot be given because even a disordered individual can be happy. Further measures would have to be used in order to correctly identify mental health status [3].

The sparse literature on obesity and SWB in psychology has used only Body Mass Index (BMI) as the measure of obesity. But there are several different measures of obesity along with Body Mass Index. This extension of the existing knowledge is particularly important, because BMI alone is not considered to be an adequate measure of obesity nor a sufficient predictor of obesity-related health outcomes $[4,5]$. The main reason for this is that BMI blurs the distinction between fat and fat-free mass such as muscle and bone [4, 6, 7, 8]. Self-reported health had the strongest association with all the measures of subjective wellbeing. 'Life satisfaction' scores for those who said they were in bad health were lower on average than for people who reported good or very-good health. People of normal weight have been found to have highest wellbeing scores compared with those who were overweight or obese. Similarly, those who perceived themselves to be the right weight had highest wellbeing scores. There is a dose relationship between the number of portions of fruit and vegetables consumed per day and levels of wellbeing in adults: an increase in the number of portions consumed corresponded with an increase in wellbeing.

There is a growing strand of empirical research that studies whether obese people are less satisfied [912]. Many of these findings, however, provide only limited insights regarding the role of self-control problems, as the correlations can be due to third variables affecting both eating behavior and subjective well-being, or because low life satisfaction and stress can lead to obesity [13]. As it has been pointed out 
before, although several investigations have studied the relationship between depression, anxiety and eating disorder, not many researchers have focused on the subjective well-being of people have eating disorders $[14,15]$, though it has been found that people with eating disorder report a significant impairment in physical and psychological quality of life compared with normal individuals. Research has demonstrated that maintaining positive levels of life satisfaction is crucial to successful adaptation in life [16]. And there are studies that have shown that decreases in life satisfaction are related to depression and anxiety [17]. Additionally, reaearch has showed that eating disorder patients usually report less quality of life, physical and psychological indicators that reflect individual welfare [18]. Although the terms quality of life and subjective well-being (SWB) are sometimes used interchangeably, these are the two terms in the field of psychology that "attempt to understand people's evaluations of their lives" [19].

Studies about Body Mass Index and subjective wellbeing seem to defend the belief that an elevated BMI coincides with low levels of wellbeing, this study yielded no results to support the idea that woman who have a normal BMI will score differently than women who are overweight or obese. A study by Jorm, Korten, Christensen, Jacomb, Rodgers and Parslow [20] stated reasons why it is assumed that those who have elevated BMI should be at a lower subjective wellbeing level.

Firstly, obesity is stigmatized on both health and aesthetic grounds. Given the social undesirability of obesity, it is not surprising that many people are trying to lose weight. Another reason for expecting an association with worse mental health is that obesity is associated with physical health problems that are risk factors for depression.

Wardle and Cooke [21] examined the impact of obesity on psychological wellbeing in adolescents in clinical and community samples and found that very few obese adolescents suffered from low levels of mental health. Also, Wardle and Cooke [21] noted a reason why there is a stereotype about obese individuals having a low subjective wellbeing level is because of the social stigma that is placed on the obese (i.e.) obese individuals are seen as unhappy because of their appearance while thin individuals are shown as happier with themselves as well as their bodies.

The assumption is that the information about the health risks of obesity, social pressure to be fit, and stigmatization and discrimination of overweight individuals can lead to a lower level of subjective wellbeing among overweight people. However, unlike the considerably clear results about the relationship between obesity and health parameters, no consistent conclusions have been made concerning how obesity is related to one's mood, satisfaction with life, emotional distress, etc. the assumption that the people who have excess weight are more preoccupied and dissatisfied with their bodies in comparison to non-overweight people has significant empirical justification although certain studies report the absence of a correlation between the level of bodyweight and dissatisfaction with the body.

When relating obesity to well-being, subjective well-being is linked to both psychological and physical aspects of an individual [22]. When a person is overweight and shows signs of psychological distress, the motivation to change their health habits on their own can be nonexistent, and if present, weight cycling can occur which is shown to be just as harmful on the body as having an elevated BMI (a BMI greater than $25.0 \mathrm{~kg} / \mathrm{m} 2$ ) [23].Participants in a study conducted by Linda Craighead, (University of Colorado, Boulder) predicted food monitoring would produce significantly more restriction (289 women), thoughts about food (287 women), and distress about weight and shape (287 women). Both the level of eating pathology and past experiences with monitoring food intake affected their choice. As eating pathology decreased, participants indicated a greater preference for appetite monitoring. The authors noted that in an earlier randomized study of 38 women with shape and weight concerns, seven to ten days of food monitoring produced significantly greater increases in preoccupation with the food and weight and significantly more guilt about food intake that did appetite monitoring.

\section{Need for the study}

Given the concerns that food monitoring may increase preoccupation and guilt about food, appetite monitoring may be a better option for early intervention and prevention of eating disorders.BMI and subjective wellbeing should remain a topic of investigation since the body of evidence is inconclusive. Some studies find a significant difference between groups in wellbeing scores while other studies do not. Either way, it is important to examine what makes some individuals have higher levels of wellbeing than others because clinicians will be able to help individuals re-examine their priorities and better understand how to construct an environment that enhances their wellbeing.

\section{METHODOLOGY}

Aim

To find the relationship between Body Mass Index, Food Preoccupation and Subjective Wellbeing. This study focused on the significance of preoccupation towards food, Body Mass Index and life satisfaction or Subjective Wellbeing, in the life of Young Adults.

\section{Objectives}

- To explore the relationship between Body Mass Index and Preoccupation towards Food.

- To explore the relationship between the Body Mass Index of young adults and the extent to which they 
have a Positive valence towards their food preoccupation.

- To explore the relationship between the Body Mass Index of young adults and the extent to which they have a Negative valence towards their food preoccupation.

- To explore the relationship between the Body Mass Index of young adults and the extent to which they have a Neutral valence towards their food preoccupation.

- To explore the relationship of subjective wellbeing of young adults and their Body Mass Index.

\section{Hypotheses}

- There will be no significant relationship between Body Mass Index and Frequency of thoughts about Food among young adults.

- There will be no significant relationship between Body Mass Index and positive valence towards food among young adults.

- There will be no significant relationship between Body Mass Index, and negative valence towards food among young adults.

- There will be no significant relationship between Body Mass Index and neutral valence towards food among young adults.

- There will be no significant relationship between Body Mass Index and subjective wellbeing among young adults.

\section{Nature of Research design}

The present study adopted exposed- factor research design to explore the relation between Body mass index, Preoccupation with food and Subjective well- being among young adults.

\section{Sample}

The target group for the study was chosen by convenient sampling method, a sample of 100 young adults, both males and females between the ages of 20 to 25 years. Participants were literate and only students between the age groups of 20-25 years were included. The sample did not include illiterate students. Students below the age of 20 years and above the age of 25 years were not included in the sample.

\section{Variables}

The independent variable in this study was Body Mass Index and the dependent variables were Food Preoccupation and Subjective Wellbeing.

\section{Tools}

The following were the tools used for the present study

- $\quad$ BMI was measured by asking the participants their Height and Weight. BMI was calculated based on measures of height and weight.

- Food Preoccupation Questionnaire[24]

- Satisfaction with Life Scale [25]

\section{Description of the tools}

Body mass index -Body mass index was measured by asking the participants their Height and Weight. BMI was calculated based on measures of height and weight;

The Food Preoccupation Questionnaire -Food Preoccupation Questionnaire developed by Tapper, K. \& Pothos, E.M., [24] began with a series of 39 statements, generated by the authors, relating to thoughts about food. Of these, 10 were designed to assess thought frequency, and 29 to assess emotional valence of thoughts, which could be either positive (11 items), negative (11 items) or neutral ( 7 items;). These were followed by 27 similar filler items relating to thoughts about work. Participants were asked to rate the extent to which they agreed or disagreed with each statement on a 5-point scale ('completely disagree', 'disagree a bit', 'neither agree nor disagree', 'agree a bit', 'completely agree'). Four items were reverse scored. For the Food Preoccupation Questionnaire means across all participants were first computed for each item. These ranged from 1.98 to 4.03 suggesting no items were resulting in consistently extreme scores. An initial factor analysis suggested that there were three main factors accounting for $19.76 \%, 15.51 \%$ and $9.44 \%$ of the variance. Items Development and validation showing high loadings on these factors tended to be related to negative thoughts, positive thoughts and frequency of thoughts respectively.

Satisfaction with Life Scale -Satisfaction with Life Scale given by Diener, E., R.J. Emmons, R.J. Larsen and S. Griffin [25] which consists of five questions. The Satisfaction with Life Scale (SWLS) is a single scale that is used by UNESCO, the CIA, the New Economics Foundation, the WHO, the Veenhoven Database, the Latin barometer, the Afro barometer, and UNHDR to measure how one views his or her selfesteem, well-being and overall happiness with life. The Validity of SWLS (Quantitative) is: Adequate criterion validity, good convergent and discriminant validity. A number of studies were found to support the validity of the Satisfaction with Life Scale [26]. Reliability has been demonstrated in terms of high internal consistency with a value of 0.87 and stability overtime with a testretest coefficient of 0.82 .

\section{Procedure}

The data collection process took about two weeks. Informed consent was obtained from the samples. The sample was given a demographic profile followed by measuring Body mass index and administrated Food preoccupation Questionnaire and Satisfaction with life scale. Throughout the data gathering, participants were clearly informed that their participation was voluntary and that anonymity would be maintained. 


\section{STATISTICAL ANALYSIS}

SPSS (Statistical Package for Social Science) software package (windows version 13.0) was used to analyse the data. Descriptive statistics was used to analyse the baseline data and Karl Pearson product moment correlation was done to determine any significant differences relationship between the variables.

\section{RESULTS AND DISCUSSIONS}

Table-3.1: Shows the mean age of the sample

\begin{tabular}{|c|c|c|}
\hline Sample Characters & Mean & Standard Deviation \\
\hline Age & 22.2 & 1.2 \\
\hline
\end{tabular}

From the above table, it is inferred that the mean age of the sample is 22.2 with a standard deviation of 1.2. Thus, the mean age of the sample were 22 years.

Table-3.2: Shows sample characteristics

\begin{tabular}{|l|l|l|}
\hline \multirow{2}{*}{ Sample Characteristics } & \multicolumn{3}{|l|}{ Gender } \\
\cline { 2 - 3 } & Male & Female \\
\hline Frequency & 54 & 46 \\
\hline Percentage & $54 \%$ & $46 \%$ \\
\hline
\end{tabular}

Table 2 shows the frequency and percentage values of the students. The frequency of Male students is 54 and $54 \%$ respectively. The frequency of Female students is 46 and $46 \%$ respectively.

Table-3.3: Shows the correlations between Body Mass Index and Preoccupation about food (Frequency of thoughts about food)

\begin{tabular}{|c|c|c|}
\hline Statistical Measure & N & Correlation Co- efficient (r) \\
\hline Body Mass Index and Frequency of thoughts about food & 100 & 0.04 (NS) \\
\hline
\end{tabular}

From the above table, the computed correlation value between body mass index and frequency of thoughts was found to be 0.04 which is not significant at 0.01 level, thus the Hypothesis number 1'There will be no significant relationship between Body Mass Index and Frequency of thoughts about Food among Young Adults.' is accepted. It is assumed that people who are obese are more preoccupied with thoughts about food. But it is not always the case. Other factors such as Genetics, Lifestyle choices and Exercise also play a vital role.

Table-3.4: Shows the correlations between Body Mass Index and Preoccupation about food (emotional valence of thoughts)

\begin{tabular}{|c|c|c|}
\hline Statistical Measure & $\mathbf{N}$ & Correlation Co- efficient (r) \\
\hline Body Mass Index and Positive emotional valence of thoughts & 100 & $0.06(\mathrm{NS})$ \\
\hline Body Mass Index and Negative emotional valence of thoughts & 100 & $0.06(\mathrm{NS})$ \\
\hline Body Mass Index and Neutral emotional valence of thoughts & 100 & $0.02(\mathrm{NS})$ \\
\hline
\end{tabular}

From the above table, the correlation value computed between body mass index and positive emotional valence of thoughts was found to be is 0.06 , which is not significant at 0.01 level, thus the Hypothesis number 2 - 'There will be no significant relationship between Body Mass Index and positive valence towards food among Young Adults' is accepted. The reasons for this could be because the samples may not place much importance to food as a source of reward, which help them feel better about themselves. Similarly, the correlation value computed between body mass index and negative emotional valence of thoughts was found to be 0.06 , which is not significant at 0.01 level, Hence the Hypothesis number 3 - 'There will be no significant relationship between Body Mass Index, and negative valence towards food among Young Adults' is accepted. The factors which could contribute to this could be because of media images and sensationalism. Being obese and thinking about food constantly is shunned by society because being thin is considered healthy. But the samples in this study do not worry about the various things portrayed by the media, thus the correlation level is low. Further the correlation value computed between body mass index and neutral emotional valence of thoughts was found to be 0.02 , which is not significant at 0.01 level thus the Hypothesis number 4-'There will be no significant relationship between Body Mass Index and neutral valence towards food among Young Adults' is accepted. The samples are neither positively affected nor negatively affected with the thoughts about food. They do not give much importance and consider eating food, just another part of their life. 
Table-3.5: Shows the correlations between Body Mass Index and Subjective well- being

\begin{tabular}{|l|c|c|}
\hline Statistical Measure & N & Correlation Co- efficient (r) \\
\hline Body Mass Index and subjective well-being & 100 & 0.06 \\
\hline
\end{tabular}

From the above table, the correlation value computed between body mass index and subjective well- being was found to be 0.06 , which is not significant at 0.01 , thus the Hypothesis number 5 'There will be no significant relationship between Body Mass Index and subjective wellbeing among Young Adults' is accepted. Body Mass Index is not necessarily the only determinant to measure subjective well- being. There are many variables that affect Life Satisfaction such as Socioeconomic Status, educational qualification, interpersonal relationships etc that a bigger determinant of subjective well- being. From the data collected, it was observed that all the hypotheses were accepted since the correlation level values were low. Body Mass Index as a variable did not have significant relationships with Positive emotional valence, Negative Emotional valence, Neutral emotional valence as well as Life Satisfaction. The samples may not look at food as an external source of reward and do not feel extreme happiness with the thoughts about food. The sample did not have much of media influence regarding the thoughts about food. They do not consider food as a negative aspect which harms their body and self-image. There was no significant relationship between Body Mass Index and Neutral emotional valence. The samples may not have extreme thoughts about food and have a neutral stance and are unaffected. The final hypothesis which was between Body Mass Index and Satisfaction with Life also did not have a significant relationship as Body Mass Index is not the sole determinant of life satisfaction. Other determinants such as family relationships, societal position, and socio-economic status play a role as well.

\section{CONCLUSION}

The present study found that there was no significant relationship between Body Mass Index and Positive emotional valence. The present study found that there was no significant relationship between Body Mass Index and Negative emotional valence. The present study found that there was no significant relationship between Body Mass Index and Neutral emotional valence. There was also significant relationship found between Subjective wellbeing and Body Mass Index.

\section{Implication of the study}

This research has highlighted certain significant aspects. Societal ideals about Body Mass Index are highly skewed. Contrary to popular beliefs and various media portrayals that people with higher body mass index are more preoccupied with food and are less satisfied in life, has got little truth in them. People's judgments of their subjective well-being allow for a nuanced evaluation of high body weight.
According to the basic hypothesis, we expect people with higher Body Mass Index to negatively affect the subjective well-being of people. For these people, obesity is not the outcome of rational food consumption, but rather of time-inconsistent behaviour. Body Mass Index is not considered as a good determinant of life satisfaction. This research goes on to show that other factors can also play a role in being satisfied in life. People may be overweight due to reasons that are genetic and environmental in nature. Body Mass Index cannot be the sole to food preoccupation as well as subjective wellbeing because people who are extremely thin, may eat twice as much as overweight people and still be skinny, and unsatisfied in life.

There are important implications for practice as well. Health professionals need to understand that maintaining a healthy weight is important but be mindful of other factors such as low subjective wellbeing is not a direct consequence of high Body Mass Index. Focus on promoting healthy eating behaviours attitudes which lead to better self-esteem, body satisfaction and overall wellbeing.

\section{LIMITATIONS}

Body Mass Index is not always reliable in nature. In this research, only correlation was found. No cause and effect relationship was not explored. Social Desirability could have affected data collection process.

\section{REFERENCES}

1. Blundell JE and Gillett A. Control of food intake in the obese. Obesity research. 2001; 9(S11), 263S270S.

2. Silva J, Nichols J, Theunissen TW, Guo G, van Oosten AL, Barrandon O, Wray J, Yamanaka S, Chambers I, Smith A. Nanog is the gateway to the pluripotent ground state. Cell. 2009 Aug 21;138(4):722-37.

3. Diener E, Suh EM, Lucas RE, Smith HL. Subjective well-being: Three decades of progress. Psychological bulletin. 1999 Mar;125(2):276.

4. Burkhauser RV, Cawley J. Beyond BMI: the value of more accurate measures of fatness and obesity in social science research. Journal of health economics. 2008 Mar 1;27(2):519-29.

5. Ripke S, Sanders AR, Kendler KS, Levinson DF, Sklar P, Holmans PA, Lin DY, Duan J, Ophoff RA, Andreassen OA, Scolnick E. Genome-wide association study identifies five new schizophrenia loci. Nature genetics. 2011 Oct;43(10):969.

6. Johansson J. The politics of possibility: Leadership in changing times. Dunmore Pub.; 2009. 
7. Wada R, Tekin E. Body composition and wages. Economics \& Human Biology. 2010 Jul $1 ; 8(2): 242-54$.

8. Bozoyan C, Wolbring T. Fat, muscles, and wages. Economics \& Human Biology. 2011 Dec $1 ; 9(4): 356-63$.

9. Ball K, Crawford D, Kenardy J. Longitudinal relationships among overweight, life satisfaction, and aspirations in young women. Obesity research. 2004 Jun;12(6):1019-30.

10. Katsaiti MS. Obesity and happiness. Applied Economics. 2012 Nov 1;44(31):4101-14.

11. McElroy DJ, Cloud EH, inventors; Micron Technology Inc, assignee. Imaging system having redundant pixel groupings. United States patent US 6,756,576. 2004 Jun 29.

12. Needham BL, Crosnoe R. Overweight status and depressive symptoms during adolescence. Journal of Adolescent Health. 2005 Jan 1;36(1):48-55.

13. Korkeila M, Kaprio J, Rissanen A, Koskenvuo M, Sörensen TI. Predictors of major weight gain in adult Finns: stress, life satisfaction and personality traits. International journal of obesity. 1998 Oct;22(10):949-57.

14. Doll TE, Frimmel FH. Cross-flow microfiltration with periodical back-washing for photocatalytic degradation of pharmaceutical and diagnostic residues-evaluation of the long-term stability of the photocatalytic activity of $\mathrm{TiO} 2$. Water Research. 2005 Mar 1;39(5):847-54.

15. Padierna A, Quintana JM, Arostegui I, Gonzalez N, Horcajo MJ. The health-related quality of life in eating disorders. Quality of Life Research. 2000 Jun 1;9(6):667-74.

16. Deiner JT. Latin American Political Economy in the Age of Neoliberal Reform: Theoretical and Comparative Perspectives for the 1990s.
17. Rohde P, Lewinsohn PM, Seeley JR. Comorbidity of unipolar depression: II. Comorbidity with other mental disorders in adolescents and adults. Journal of abnormal psychology. 1991 May;100(2):214.

18. Felce, D., \& Perry, J. (1995). Quality of life: Its definition and measurement. Research in developmental disabilities, 16(1), 51-74.

19. Diener ED, Emmons RA, Larsen RJ, Griffin S. The satisfaction with life scale. Journal of personality assessment. 1985 Feb 1;49(1):71-5.

20. Jorm AF, Korten AE, Christensen H, Jacomb PA, Rodgers B, Parslow RA. Association of obesity with anxiety, depression and emotional well-being: a community survey. Australian and New Zealand journal of public health. 2003 Aug;27(4):434-40.

21. Wardle J, Cooke L. The impact of obesity on psychological well-being. Best practice $\&$ research clinical endocrinology \& metabolism. 2005 Sep $1 ; 19(3): 421-40$.

22. Kaplan RM, Bush JW, Berry CC. Health status: types of validity and the index of well-being. Health services research. 1976;11(4):478.

23. Packer J. The role of stigmatization in fat people's avoidance of physical exercise. Women \& therapy. 1989 Oct 31;8(3):49-63.

24. Tapper K, Pothos EM, Lawrence AD. Feast your eyes: hunger and trait reward drive predict attentional bias for food cues. Emotion. 2010 Dec;10(6):949.

25. Diener ED, Emmons RA, Larsen RJ, Griffin S. The satisfaction with life scale. Journal of personality assessment. $1985 \mathrm{Feb}$ 1;49(1):71-5.

26. Diener Ed. Subjective well-being. Psychological Bulletin.1984; 95(3): 542-575. 